\title{
Correction to: Topological characterization of hexagonal and rectangular tessellations of kekulenes as traps for toxic heavy metal ions
}

\author{
Micheal Arockiaraj ${ }^{1} \cdot$ S. Prabhu ${ }^{2} \cdot$ M. Arulperumjothi ${ }^{3} \cdot$ S. Ruth Julie Kavitha ${ }^{1} \cdot$ Krishnan Balasubramanian $^{4}$
}

Published online: 23 July 2021

(c) Springer-Verlag GmbH Germany, part of Springer Nature 2021

\section{Correction to: \\ Theoretical Chemistry Accounts (2021) 140:43 \\ https://doi.org/10.1007/s00214-021-02733-0}

In the original publication of this article, the links to Google scholar were missing for the references $[60,65,66,70$ and 71] and hence they were not redirected to appropriate articles on the Springer website.

This erratum now corrects the same.

The original article has been updated.

Publisher's Note Springer Nature remains neutral with regard to jurisdictional claims in published maps and institutional affiliations.

The original article can be found online at https://doi.org/10.1007/ s00214-021-02733-0.

Krishnan Balasubramanian

baluk@asu.edu

1 Department of Mathematics, Loyola College, Chennai 600034, India

2 Department of Mathematics, Sri Venkateswara College of Engineering, Sriperumbudur 602117, India

3 Department of Mathematics, Loyola College, University of Madras, Chennai 600034, India

4 School of Molecular Sciences, Arizona State University, Tempe, AZ 85287-1604, USA 